\title{
INTERNATIONAL STANDARDISATION WORK ON THE MEASUREMENT OF RADON IN AIR AND WATER
}

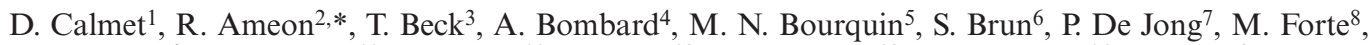
M. Fournier ${ }^{9}$, M. Herranz ${ }^{10}$, S. Jerome ${ }^{11}$, A. Klett ${ }^{12}$, P. Kwakman ${ }^{13}$, M. Llaurado ${ }^{14}$, J. Loyen ${ }^{2}$, R. Michel ${ }^{15}$, P. Nardoux ${ }^{16}$, T. Richards ${ }^{17}$, C. Schuler ${ }^{18}$, S. Tokonami ${ }^{19}$ and M. Woods ${ }^{20}$

${ }^{1}$ Commissariat à l'Energie Atomique, Direction des Applications Militaires, BP12, 91680 Bruyères le Châtel, France

${ }^{2}$ Institut de Radioprotection et de Sûreté Nucléaire, Direction de l'Environnement et de l'Intervention, BP17, 92262 Fontenay-aux-Roses, France

${ }^{3}$ Federal Office for Radiation Protection, Koepenicker Allee 120-130, 10318 Berlin, Germany

${ }^{4}$ TrisKem International, Campus de Ker Lann, Parc de Lormandière, Rue Maryse Bastié, 35170 Bruz,

France

${ }^{5}$ International Organization for Standardization, 1, ch. de la Voie-Creuse, Case postale 56, CH-1211 Geneva 20, Switzerland

${ }^{6}$ Commissariat à l'Energie Atomique, DEN/DSP/SPR/LRCE, 91191 Gif-sur-Yvette, France

${ }^{7}$ Nuclear Research and Consultancy Group (NRG), PO Box 9034, 6800 ES Arnhem, The Netherlands

${ }^{8}$ ARPA Lombardia, Dipartimento di Milano-U.O. Agenti Fisici, Via Juvara 22, 20129 Milano, Italy

${ }^{9}$ Autorité de Sûreté Nucléaire, Direction de l'environnement et des situations d'urgence, 6 place du Colonel Bourgoin, 75572 Paris Cedex 12, France

${ }^{10}$ Department of Nuclear Engineering and Fluid Mechanics (UPV/EHU), alda Urquijo s/n, 48013 Bilbao, Spain

${ }^{11}$ The National Physical Laboratory, Queens Road, Teddington, Middlesex TW11 0LW, UK

${ }^{12}$ Berthold Technologies GmbH \& Co KG, Calmbacherstrasse 22, 75323 Bad Wildbad, Germany

${ }^{13}$ RIVM, Laboratory for Radiation Research, PO Box 1, 3720 BA Bilthoven, The Netherlands

${ }^{14}$ Departamento Química Analytíca, Laboratori de Radiologia Ambiental, Facultat de Química-Universitat de Barcelona, Martí i Franquès, 1-11, 08028 Barcelona, Spain

${ }^{15}$ Strahlenschutz und Radioökologie, Wilh-Henze-Weg 14, D-31303 Burgdorf, Germany

${ }^{16}$ AREVA NC, SEPA/SAN, BP71, 87250 Bessines, France

${ }^{17}$ BSI, 389 Chiswick High Road, London W4 4AL, UK

${ }^{18}$ Paul Scherrer Institut, Division for Radiation Safety and Security, Calibration Laboratory, CH-5232 Villigen PSI, Switzerland

${ }^{19}$ National Institute of Radiological Sciences (NIRS), Research Center for Radiation Protection,

4-9-1 Anagawa, Inage-ku, Chiba 263-8555, Japan

${ }^{20}$ Ionising Radiation Metrology Consultants Ltd, Teddington, Middlesex, UK

*Corresponding author: roselyne.ameon@irsn.fr

Radon is considered to be the main source of human exposure to natural radiation. As stated by the World Health Organization, the exposure due to the inhalation of indoor radon is much greater than the one via the ingestion of water as radon degasses from water during handling. In response to these concerns about the universal presence of radon, environmental assessment studies are regularly commissioned to assess the radon exposure of public and workers. The credibility of such studies relies on the quality and reliability of radon analysis as well as on the sample representativeness of the radiological situation. The standard-setting approach, based on consensus, seemed to lend itself to a settlement of technical aspects of potential comparison. At present, two Working Groups of the International Standardization Organization are focussing on drafting standards on radon and its decay products measurement in air and water. These standards, which aim for a set of rigorous metrology practices, will be useful for persons in charge of the initial characterisation of a site with respect to natural radioactivity as well as to those performing the routine surveillance of specific sites.

\section{INTRODUCTION}

${ }^{222} \mathrm{Rn}$ is considered to be the main source of human exposure to natural radiation. Concerning the risk linked to radon exposure, as stated by the World Health Organization (WHO), the greatest exposure is due to the inhalation of indoor short-lived decay products of radon ${ }^{(1)}$. In most dwellings, the largest part of radon originates from the soil and infiltrates the building by advective and diffusive flows. Other sources, including building materials and water 


\section{CALMET ET AL.}

extracted from wells, are of less importance in most circumstances.

Since radon is estimated to contribute up to $52 \%$ of the total natural internal dose, environmental assessment studies are regularly commissioned to assess the radon exposure of the public ${ }^{(2)}$. The credibility of such studies relies on the quality and reliability of radon analysis as well as the sample representativity of the radiological situation.

The recent expansion from national stakeholders to a worldwide perspective requires that the various measurements are reliable and reproducible to make them comparable with similar measurements performed in other parts of the world. The standardsetting approach at the international level, based on consensus, seemed to lend itself to a settlement of technical aspects of potential comparison. Two international organisations, the International Electrotechnical Commission (IEC) and the International Standardization Organization (ISO) applying the principles of the World Trade Organization on transparency, openness, impartiality and consensus, effectiveness and relevance, coherence and addressing the concerns of developing countries are involved in standardisation of radon measurement.

These standards will be useful for persons in charge for the initial characterisation of a site with respect to the natural radiation burden as well as to those performing the routine surveillance of radon activity levels, which includes systematic and periodic inspection of specific sites, such as those in the radon-prone areas. These standards aim for a set of rigorous metrology practices in order to ensure the comparability of the results obtained in the various countries. This document describes the work under way at ISO on the measurement of ${ }^{222} \mathrm{Rn}$ and its short-lived decay products in the indoor and outdoor atmosphere and ${ }^{222} \mathrm{Rn}$ in water.

\section{ORGANISATION OF STANDARDISATION IN THE NUCLEAR FIELD AT THE INTERNATIONAL LEVEL}

At the international level, IEC and ISO endeavour to set up a rigorous metrology practices for measuring, among other things, radionuclides activity in order to ensure the comparability of the results obtained in the various Member States of these organisations.

The IEC publishes standards for all fields of electrotechnology. Within IEC, Technical Committee TC45 covers nuclear instrumentation and equipment, including radiation protection instruments. In 2000, IEC published a standard that deals with electronic devices for the measurement of radon and radon decay products (IEC 61577).
The ISO is a non-governmental organisation that forms a network of the national standards institutes of 163 countries in charge of promoting the development and publication of International Standards. ISO standards are developed by technical committees (3238 committees at the end of 2009) comprising experts from the industrial, research and business sectors which have requested for such standards, and which subsequently put them to use. These experts may be joined by representatives of governmental agencies, testing laboratories, consumer associations, non-governmental organisations and academic circles. Therefore, every ISO standard is the result of a consensus to be reached on solutions that meet both the requirements of business and the broader needs of society.

The national delegations of experts of a committee meet to discuss, debate and argue until they reach consensus on a draft agreement. The resulting document is circulated as a Draft International Standard to all ISO's member bodies for voting and comment, through public consultation within the countries. If voting is in favour, the document, with eventual modifications, is circulated to the ISO members as a Final Draft International Standard. If that vote is positive, the document is then published as an International Standard.

Supplement to the work done on equipment standardisation by the IEC, two ISO Technical Committees are presently drafting standards on the measurement of radon concentrations in air and in water as well as its release into indoor and outdoor environments. These are the TC85 on Nuclear Energy, nuclear technologies and radiological protection, with its working group 17 on Radioactivity Measurement of the Sub-Committee 2 on Radiological protection (TC85/SC2/WG17) and the TC147 on Water Quality with the Working Group 4 on Radiological Measurement (TC147/WG4). TC85 and $\mathrm{TC} 147$ have respectively 24 and 35 states as participating members and 6 and 52 states with an observer status. Among them, 13 states participate in the drafting of the radon standards in TC85/SC2/ WG17 and 14 states in TC147/WG4.

\section{STANDARDISATION WORK ON ${ }^{222} \mathrm{RN}$ MEASUREMENT}

\section{Radon measurement in the atmosphere}

In 2007, ISO/TC85 members decided that drafting a new standard on the measurement of the activity concentration of ${ }^{222} \mathrm{Rn}$ and its short-lived decay products in the atmosphere (ISO 11665) was of global relevance and appropriate to the relevant sectors and stakeholders. Thus the standard-setting work of the TC85/WG17 on ISO 11665 is related to the general guidelines for sampling and radiation detection and 


\section{INTERNATIONAL STANDARDISATION WORK ON RADON MEASUREMENT}

intended for laboratories responsible for the monitoring of radon in indoor and outdoor environments. ISO 11665 is organised in nine parts (Figure 1).

The radon activity concentrations in air sampled above continental areas vary over five orders of magnitude, between a few Becquerels per cubic metre and several thousand Becquerels per cubic metre. Indoor radon activity concentrations are ranging from $<10$ Bq. $\mathrm{m}^{-3}$ to several hundreds of Becquerels per cubic metre ${ }^{(2)}$. Activity concentration can reach several thousands of Becquerels per cubic metre in very confined spaces, such as underground workplace and caves, or in houses built on uranium rich soils ${ }^{(3-5)}$.

The radon activity concentration, as well as the potential alpha energy concentration of its decay products, varies tremendously during the day time, from day to day, during the seasons. More than one order of magnitude variation can be observed over a short period of time at the same place, and thus measurement results will depend on the sampling duration which may extend from a few minutes to several months, as well as the season of the sampling date. The extrapolation from an average activity concentration obtained from a measurement performed during a given sampling duration at a given sampling time to an average activity concentration representative of a different sampling duration and/ or sampling season requires the knowledge of the radon activity variability over the inferred period. In some cases, the uncertainty attached to this variability may be so large that such an extrapolation becomes meaningless for the objective of the intended use of the measurement date. It is therefore

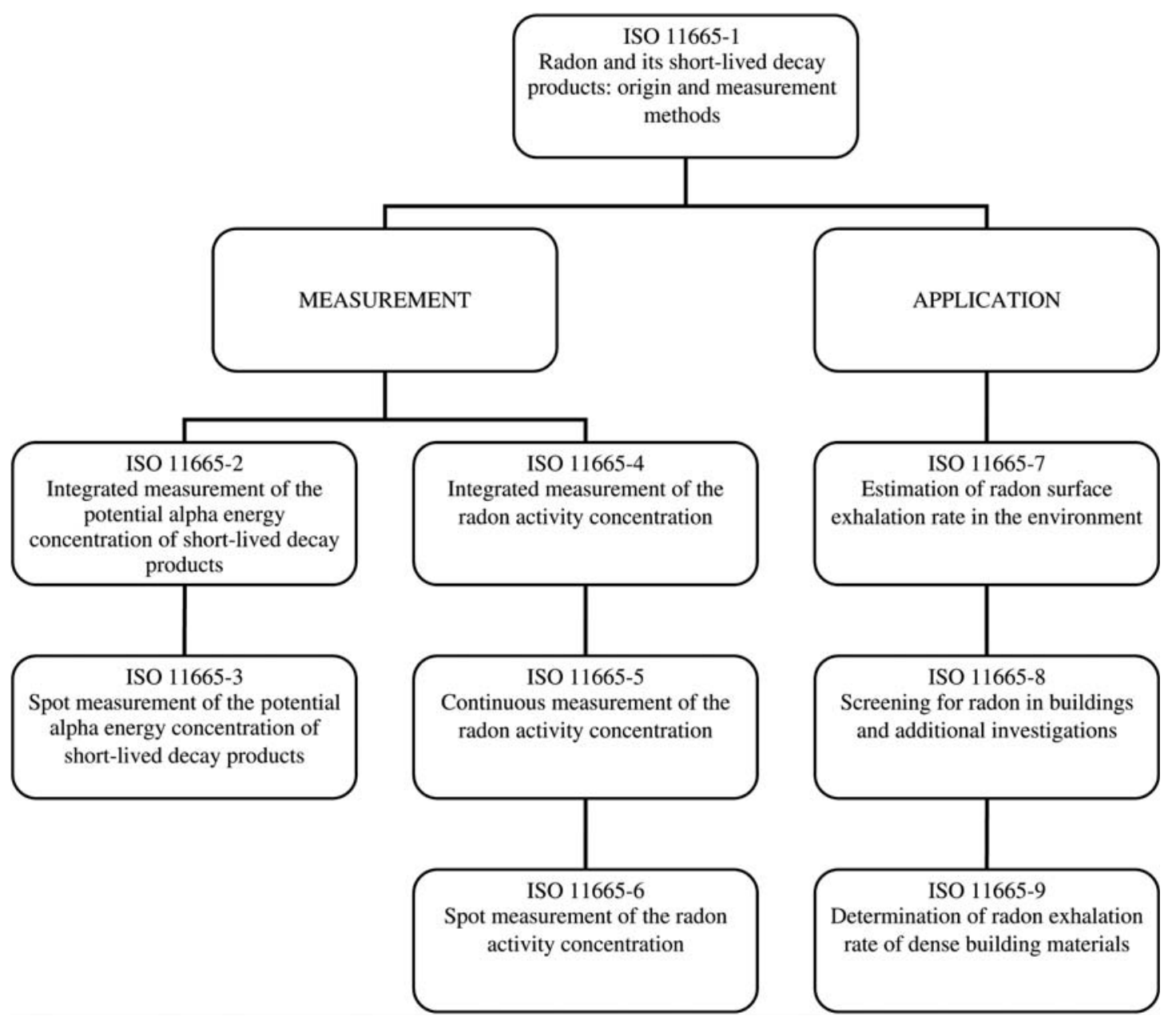

Figure 1. Structure of ISO 11665 standard. 


\section{CALMET ET AL}

important that the choice of the sampling method, duration and season of sampling are compatible with the intended use of the data as well as the level of the associated uncertainty.

Depending on the duration of the sampling phase, three types of measurement methods are distinguished:

- Spot measurement method that gives indications, at the scale of a few minutes at a given point, of the radon activity concentration or the potential alpha energy concentration of short-lived radon decay products in open and confined atmospheres (ISO 11665-3 and ISO 11665-6);

- Continuous measurement method that allows the assessment of temporal changes in radon activity concentration in the environment, in public buildings, homes and workplaces, as a function of ventilation and/or meteorological conditions (ISO 11665-5);

- Integrated measurement method that gives indications of the average activity concentration of ${ }^{222} \mathrm{Rn}$ or of the average potential alpha energy concentration of short-lived radon decay products in the air over periods varying from a few days to $1 \mathrm{y}$. Application of long-term integrated measurement methods is the appropriate way to assess the human exposure to radon and its decay products (ISO 11665-2 and ISO 11665-4).

On the basis of these parts of ISO 11665 dealing with the measurement methods, the WG17 drafted three application standards. Two of them concern the characterisation of the release of radon in the atmosphere. ISO 11665-9 deals with the determination of the radon exhalation rate of building materials under laboratory conditions whereas ISO $11665-7$ gives guidelines on estimating the ${ }^{222} \mathrm{Rn}$ surface exhalation rate (of soil, rock, building interface, wall) in the environment in the field of on-site investigations likes the search of radon sources or comparative studies of exhalation rate on the same site.

According to the recommendations of WHO on the need of standardised indoor radon protocols to ensure accurate and consistent measurements, WG17 members drafted ISO 11665-8, which is of particular interest in risk management. This standard covers the applicable requirements to determine the annual average activity concentration of radon in a building and to identify the source and transfer paths of the radon in this building. These requirements apply also to the effectiveness control and the sustainability of remedial actions.

\section{Radon measurement in water}

In general, radon issued from the soil is the main source of indoor radon. However, in some cases such as spa centres or water treatment plants, the radon degassed from water is a major contribution to the ionising radiation dose received by the public and workers $(6,7)$. The use of radon-rich water for washing and cooking in homes may also result in increasing radon activity concentration in indoor air due to degassing. For a typical house, it is estimated that $10 \mathrm{~Bq} \cdot 1^{-1}$ of ${ }^{222} \mathrm{Rn}$ in the water contribute 1 Bq. $\mathrm{m}^{-3}$ of indoor air ${ }^{(8-10)}$. Knowledge of the amount of radon in water is an important element in policies relating to the health risks linked to this gas $^{(11)}$. Measurements of the radon activity concentration in water are also of great interest to hydrogeologists. Knowledge of radon activity concentrations in deep aquifers provides important information on the structure of these aquifers, on the Earth's crust in general, and on the presence of uranium ores in the surrounding rock. They can also be used to discriminate between ground water and surface water as the latter is more sensitive to the influence of rainfall.

Radon is present in all occurring surface and ground water, with activity concentrations ranging from a few Becquerels per litre (surface water) to several thousand Becquerels per litre (deep aquifers, boreholes, geothermal springs, etc. $)^{(12)}$. The radon originates mainly from radon diffusion from rock into water and to a lesser extent, from the radioactive decay of ${ }^{226} \mathrm{Ra}$ dissolved in the water.

In May this year, ISO TC147 State members approved the drafting of a new standard on the measurement of the activity concentration of ${ }^{222} \mathrm{Rn}$ and its short-lived decay products in water (ISO 13164) to supplement the work done in the TC85. The standard-setting work of the TC147/WG4 on radon measurement in water is intended for laboratories responsible for the monitoring of radioactivity in drinking and unprocessed water as well as persons in charge of environmental studies. ISO 13164 is organised in four parts (Figure 2): the first one (ISO 13164-1) covering the applicable requirements for collecting, packaging and transporting water samples, for the determination of the radon content in water. The other three parts deal with specific measurement methods of the activity concentration of ${ }^{222} \mathrm{Rn}$ in water. These methods fall into two categories:

- direct measurement of the water sample with no transfer of phase: ISO 13164-2 describes the determination of ${ }^{222} \mathrm{Rn}$ activity concentration in a sample of water following the measurement of its short-lived decay products by direct gamma ray spectrometry of the water sample;

- indirect measurement involving the transfer of the ${ }^{222} \mathrm{Rn}$ from the aqueous phase to another phase: ISO 13164-3 describes the measurement of ${ }^{222} \mathrm{Rn}$ in water following its transfer from the 


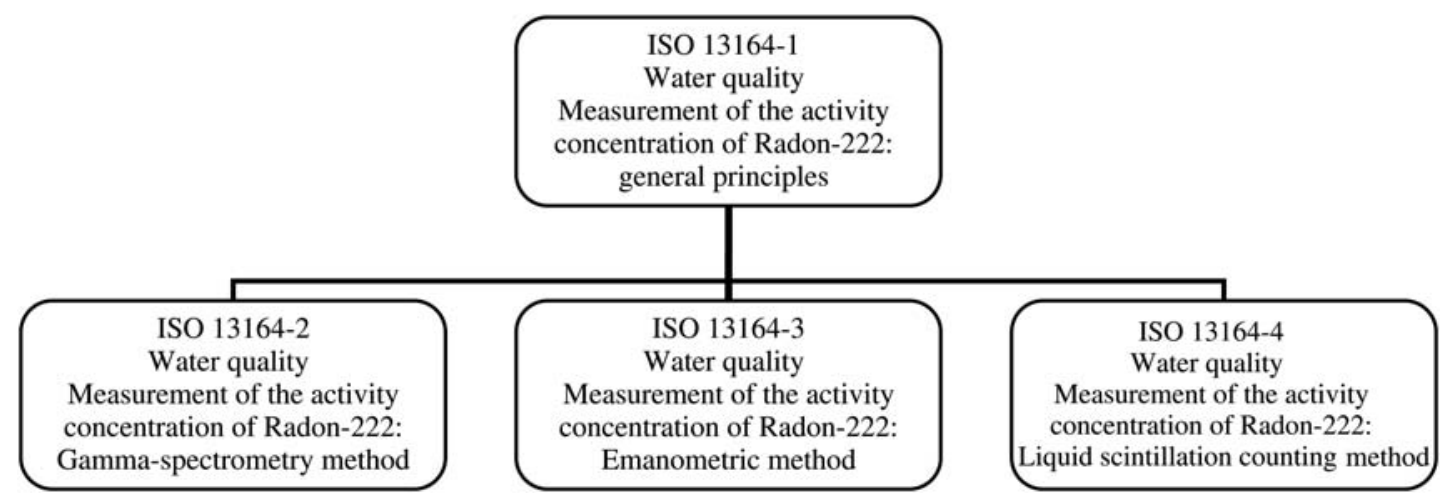

Figure 2. Structure of ISO 13164 standard.

aqueous phase to the air phase by degassing and its detection. It gives recommendations for rapid measurements performed over a period of a few hours. ISO 13164-4 deals with the measurement of ${ }^{222} \mathrm{Rn}$ in water by the liquid scintillation counting method.

All types of methods may be applied either in the laboratory or on site. The methods are applicable to all types of raw water, and the method should be selected according to the purpose of the measurement, mainly phenomenological observation and radiological impact assessment taking into account the expected level of the radon activity concentration.

\section{CONCLUSION AND PERSPECTIVES}

Radiological assessment studies are regularly commissioned to study the impact of radon on the public, in response to concern about the presence of this radionuclide by different stakeholders. The credibility of these studies depends on the reliability of radionuclide measurement in the laboratory as well as the sample representativeness of the radiological situation. The proposal in 2007 to develop a first ISO standard on radon measurement was triggered by a constant interest for this type of work at the international level that demonstrates the generic nature of this issue, the interest of which is not restricted to the national level.

The use of the ISO standard is often mandatory for laboratories seeking official certification or accreditation to ensure that the published results will be reproducible and comparable in time and space. When published, ISO 11665 and ISO 13164 will provide to laboratories in charge of radon measurement the requirements based on consensus and agreed at the international levels to assess properly the activity concentration of ${ }^{222} \mathrm{Rn}$ and its shortlived decay products in the atmosphere and water.

In the near future, the drafting of new standards on the measurement of radon in soil and the measurement of thoron in indoor air will be submitted for approval by TC85 State members. In addition to the measurement of radon in indoor air, the measurement of radon in the soil is used for the drawing up of radon potential maps. These maps may be a convenient way for the stakeholders to manage the radon risk over all the country by defining radon-prone areas in which measurement has to be performed or remedial actions have to be implemented.

Even if the contribution of ${ }^{222} \mathrm{Rn}(48 \%)$ to the global average exposure to natural radiation is far more significant than that of ${ }^{220} \mathrm{Rn}(4 \%)$, the measurement of thoron can be of particular interest in some places using building materials with enhanced level of thorium. In recent years, environmental assessment studies have been more and more commissioned to assess the thoron exposure of the public $^{(13,14)}$.

\section{REFERENCES}

1. WHO, Handbook on Indoor Radon. A Public Health Perspective. World Health Organization (2009).

2. UNSCEAR. Effects of ionizing radiation, Vol. 1, 2006, Report to the General Assembly, with Scientific Annexes. United Nations Publication (2008).

3. Duffy, J. T., Madden, J. S., Mackin, G. M., McGarry, A. T. and Colgan, P.A. A reconnaissance survey of radon in show caves in Ireland. Environ. Int. 22(1), 415-423 (1996).

4. Jovanovic, P. Radon measurements in karst caves in Slovenia. Environ. Int. 22(1), S429-S432 (1996).

5. Lario, J., Sanchez-Moral, S., Cuezva, S., Canaveras, J. C. and Soler, V. Radon continuous monitoring in Altamira Cave (northern Spain) to assess user's annual effective dose. J. Environ. Radioact. 80(2), 161-174 (2005). 


\section{CALMET ET AL.}

6. Ameon, R. Le radon dans les stations thermales: une source d'exposition aux rayonnements ionisants. Radioprotection 38(2), 201-215 (2003).

7. Körner, S. and Reifenhäuser, C. Investigation and reduction of personnel exposure levels in Bavarian water supply facilities. In: Proceedings of the 9th European ALARA Network Workshop Occupational Exposure to Natural Radiation, Augsburg, Germany, 18-21 October 2005.

8. Gesell, T. F. and Prichard, H. M. The contribution of radon in tap water to indoor concentrations. In: Gesell, T. F. and Prichard, H. M., Eds. Natural Radiation Environment III. NTIS; DOE CONF 780422, pp. 1347-1363 (1980).

9. Nazaroff, W. W., Doyle, S. M., Nero, A. V. and Sextro, R. G. Potable water as a source of airborne $222 R n$ in U.S.: dwellings. A review and assessment. Health Phys. 52, 281-295 (1987).

10. Hess, C. T., Michel, J., Horton, T. R., Prichard, H. M. and Coniglio, W. A. The occurrence of radioactivity in public water supplies in the United States. Health Phys. 48, 553-586 (1985).

11. WHO. Guidelines for Drinking-Water Quality, Volume 1, Recommendations. Third edition incorporating the first and second, Addenda (2008).

12. EC. Commission recommendation of 20 December 2001 on the protection of the public against exposure to radon in drinking water supplies (notified under document number C(2001) 4580) Official Journal of the European Communities No. L 344, pp. 85-88 (2001).

13. Tokonami, S. International Workshop on the Environmental Thoron and Related Issues, Chiba, Japan, May 19-22 (2010).

14. McLaughlin, J., Murray, M., Currivan, L., Pollard, D., Smith, V., Tokonami, S., Sorimachi, A. and Janik, M. Thoron and its Airborne Progeny in Irish Dwellings. Third European IRPA Congress, Helsinki, Finland, June 14-18 (2010). 